\title{
Flesh-eating disease: A note on necrotizing fasciitis
}

\author{
H Dele Davies MD MSc
}

$\mathrm{T}$ here has been much media attention in the past few years to the condition dubbed 'flesh-eating disease', which refers, primarily, to a form of invasive group A beta hemolytic streptococcal (GABHS) infection that leads to fascia and muscle necrosis. In 1999, the Canadian Paediatric Society issued a statement on the state of knowledge and management of children, and close contacts of persons with all-invasive GABHS disease (1). The present note is intended to deal specifically with necrotizing fasciitis (NF) by providing an update on the limited current state of knowledge, diagnosis and management. Surveillance to establish actual national rates and epidemiology of NF through the Canadian Paediatric Society is proposed.

\section{DEFINITIONS AND EPIDEMIOLOGY}

$\mathrm{NF}$ is a deep-seated infection of the subcutaneous tissue that results in the progressive destruction of fascia and fat (2). It is a rare illness that causes extensive tissue destruction and can lead to death. There are many causes of NF, including GABHS, Clostridium perfringens, Clostridium septicum, Vibrio species and fungi of the Mucorales family. In general, NF is classified into two types. Type I NF refers to mixed infections involving anaerobes (most commonly Bacteroides and Peptostreptococcis species), and one or more facultative anaerobes, such as streptococci (non-GABHS) and members of the Enterobacteriaceae family (eg, Escherichia coli, and Enterobacter, Klebsiella and Proteus species) (3). Type II NF refers to infections that are caused by invasive GABHS. The most common type of NF is type II, which is the focus of the bulk of this note.

Invasive GABHS disease is defined by the isolation of group A streptococcus from a normally sterile site such as blood, cerebrospinal fluid or pleural fluid (4). GABHS-related
NF either may occur as a part of streptococcal toxic shock syndrome (STSS), or may occur in patients with no signs of shock or organ failure. STSS is defined as the isolation of group A streptococcus from a normally sterile site in association with hypotension and multisystem organ failure (Table 1) (5). In Canada, it is estimated that 90 to 200 cases of NF occur each year in all age groups (6), but annual national estimates in children are, largely, unknown. Although there are many case reports and case series of NF, limited popula-

\section{TABLE 1}

\section{Case definition for streptococcal toxic shock syndrome}

Isolation of group A streptococcus (Streptococcus pyogenes) from a normally sterile site (eg, blood, cerebrospinal fluid, pleural fluid)* and

Hypotension (less than fifth percentile of systolic blood pressure for children or less than $90 \mathrm{mmHg}$ for adolescents) and two or more of:

1. Renal impairment (creatinine greater than two times the upper limit for age)

2. Coagulopathy (platelets less than $100,000 \times 10^{6} \mathrm{U} / \mathrm{L}$ or evidence of disseminated intravascular coagulopathy)

3. Liver involvement (alanine aminotransferase, aspartate aminotransferase or bilirubin greater than two times the upper limit of normal)

4. Adult respiratory distress syndrome (pulmonary infiltrates and hypoxemia without heart failure or generalized edema)

5. Generalized erythematous rash that may desquamate

6. Soft tissue necrosis in the form of necrotizing fasciitis, myositis or gangrene

*If group A streptococcus is isolated from a nonsterile site (eg, throat, sputum, vagina) but the patient has hypotension and two of criteria 1 to 6 above, it is considered a probable case if no other etiology for the illness is found 
tion-based studies that involve children primarily have been published. In a large population-based study performed in Ontario from 1992 to 1996 (7), 10 children had NF with an incidence of $0.08 / 100,000$ children/year and accounted for $4 \%$ of all invasive cases. About $30 \%$ of GABHS-related NF cases are associated with STSS (7). The incidence of both type I and type II NF in the rest of Canada is unknown.

\section{CLINICAL PRESENTATION}

Type I NF typically involves the abdominal wall, perianal and groin areas, and postoperative wounds $(3,8,9)$. In newborns, type I NF may be a serious and life-threatening complication of omphalitis $(8,10)$. Erythema and edema around the umbilicus can progress within hours or days, leading to a purplish discolouration and periumbilical necrosis. Anterior abdominal wall involvement often extends to involve the flanks and chest wall. In a retrospective study involving 11 newborn infants with periumbilical NF over a 20 -year period, a total of 38 bacterial isolates was recovered involving 21 aerobic and facultative, and 17 anaerobic bacteria. Aerobic or facultative bacteria only were present in one patient, anaerobes only in two (18\%), and mixed aerobic and anaerobic flora in eight $(73 \%)$. Multiple organisms were recovered from all patients, and the number of isolates varied from two to six (average 3.5 isolates/specimen). The predominant isolates were Peptostreptococcus species (seven isolates); Bacteroides fragilis group (six isolates); streptococcus group B (four isolates); and Streptoccocus aureus, streptococcus group D, E coli and Proteus mirabilis (three isolates each). All patients underwent extensive debridement and resection, and received supportive and antimicrobial therapy. Six (55\%) of the patients died.

Type II NF has initial nonspecific clinical findings. The lack of a rash or confusion with cellulitis when a rash is present makes the early diagnosis of this form of $\mathrm{NF}$ difficult $(11,12)$. Early on, NF mostly involves the subcutaneous tissue, with normal overlying skin. Excruciating pain that is out of keeping with the clinical findings is an important clue to the diagnosis (11), and relatively high temperatures are common (12). Local evidence of an abrasion, cut or contusion at a body site are other common findings on presentation (reflecting the entry point of the GABHS). When associated with STSS, hypotension can develop within $24 \mathrm{~h}$ or as late as four weeks after the precipitating event. Fever and 'influenza-like' symptoms, such as myalgia and chills, are prominent symptoms and, often, are evident at presentation. Clues to differentiating the syndrome from influenza may include the absence of respiratory symptoms or a lack of history of close contacts with influenza-like illness, the presence of focal pain rather than generalized myalgia, and a history of recent penetrating or blunt trauma in up to $40 \%$ of patients (7). GABHS-related NF in children is most likely to occur on the lower extremities, including the thigh and groin (7). Overall, $16 \%$ of all-invasive GABHS infections in children are associated with a chronic underlying illness (7), persons with leukemia having an increased risk.

\section{ASSOCIATION WITH VARICELLA}

Varicella infection has been identified often in case series and in population-based studies as a major risk factor for invasive GABHS infections among children (4,7,13-21). Children younger than 10 years of age with chickenpox have a 58-fold increase in the risk of developing invasive GABHS disease during the two weeks after the onset of skin lesions (7). Between $6 \%$ and $37 \%$ of invasive group A streptococcal infections in children are associated with varicella $(4,7,16)$. Reports of outbreaks of invasive group A streptococcal infection and varicella in southern California (22) and Seattle (14) suggest that outbreaks may occur with the simultaneous presence of high rates of varicella, and the circulation of a virulent group A streptococcal clone in the community. Varicella may allow invasion via another less apparent portal, such as lesions in the mouth or the respiratory tract, as well as via skin lesions.

Invasive GABHS infections (most commonly cellulitis and occasionally NF) that occur as complications of varicella generally manifest four to six days after the onset of rash (7). Initially, the signs may be nonspecific, and the signs of infected pox lesions may be absent. Secondary fever (fever occurring after the resolution of initial chickenpox fever) is common (11). As noted above, a key feature of NF may be severe, localized pain that is out of proportion with the appearance of a lesion. In a case control study that was performed in Los Angeles and Orange counties (23), when children with varicella who developed invasive GABHS disease were compared with control children who had uncomplicated varicella, the former were more likely to be cared for in the home rather than at out-of-home child care; to report having asthma; to be taking albuterol; to be a secondary varicella case within a household; to report fever after day 2 of varicella; and to have contacted a health care provider later than controls (day 3.8 rather than day $1.7, \mathrm{P}<0.001)$. However, identification of these potential risk factors may not help clinicians trying to identify which child with prolonged or secondary fever may have a GABHS infection such as NF. In a Canadian study, persons with asthma were not identified to be at greater risk of invasive GABHS (7). A high index of suspicion, the occurrence of severe focal pain, documented contact with GABHS at school, home or in the hospital, and knowledge of whether other cases have occurred in the community recently may be of more help in making a diagnosis. Cases complicating chickenpox and other cases in children do not differ in the proportion of children with underlying illness or in case fatality (7). Other types of skin lesions, including eczema, also appear to increase the risk of invasive disease, presumably because they provide a focus of entry for the bacteria (11).

\section{LABORATORY FINDINGS}

The laboratory features of severe, invasive GABHS disease are nonspecific (Tables 1 and 2). The association of a normal or elevated white blood cell count with a left shift, in association with severe pain, may be the only early clue to the diagnosis of NF. An elevated creatine kinase level should alert the 
TABLE 2

Early diagnostic clues for severe invasive group A streptococcal infections*

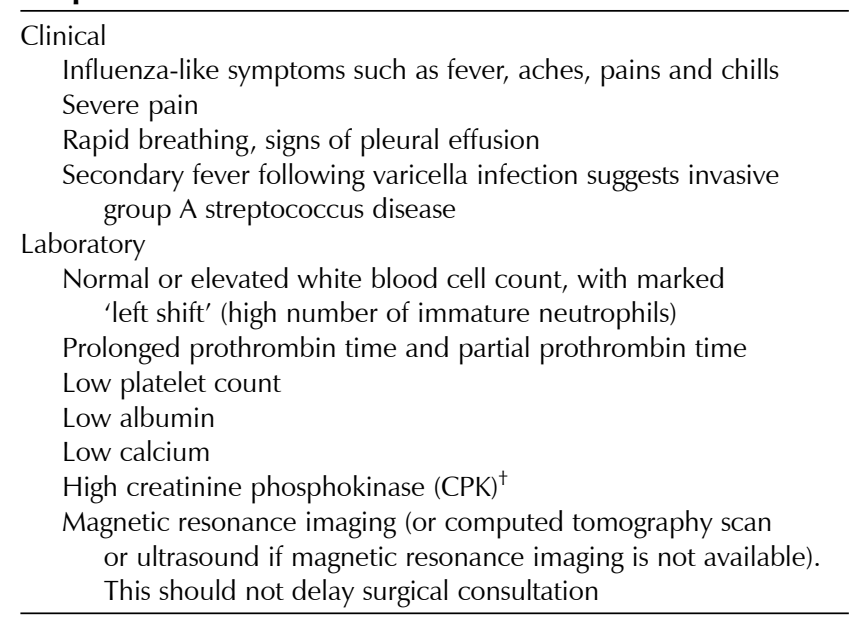

*None of the signs and laboratory features are specific, and all the features noted in Table 1 can occur at any time. ${ }^{+}$CPK elevation may be a sign of early necrotizing fasciitis with muscle involvement (myositis), but fasciitis may still occur in the presence of a normal CPK if there is no muscle involvement

clinician to muscle involvement. However, a normal creatine kinase level does not rule out fasciitis, because other fascial components alone may be involved. For type I infections, Gramstained smears of the exudate (if any or if collected during a fasciotomy) often show a mixture of organisms. The presence of numerous spores in the wound exudate with Gram-positive bacilli should lead to the suspicion of $C$ perfringens. Gram stains with type II NF show Gram-positive cocci in chains.

\section{MANAGEMENT OF NF}

Given the rapid progression of infection, patients suspected of having NF of any type must be admitted to hospital and monitored very closely, preferably under the supervision of an expert in infectious diseases. An early surgical consultation should be sought; the fascia may need to be incised for decompression and assessment of whether debridement is needed to save the affected area or the patient's life. Surgical diagnosis consists of an exploration of the affected area with frozen biopsy to look for neutrophil infiltrates at wound margins $(24,25)$. A full thickness incision down to and including the muscle fascia is indicated to examine all tissue planes and the underlying muscle, and to allow debridement of necrotic tissue. Often, multiple sequential debridements are needed.

Although imaging with magnetic resonance imaging and computed tomography scanning have been noted to be of value in diagnosing NF, surgical management should not be delayed in favour of these assessments, and the specificity of magnetic resonance imaging has been questioned recently (26). Blood cultures, as well as cultures of other normally sterile sites that appear to be involved clinically, must be obtained. For suspicion of the most common type of NF (type II or GABHS-related), the child should be started on intra- venous penicillin in high doses $(250,000$ to $400,000 \mathrm{U} / \mathrm{kg} /$ day divided into six doses) and intravenous clindamycin $40 \mathrm{mg} / \mathrm{kg}$ divided into three or four doses per day. Group A streptococci remain universally susceptible to all beta-lactam antibiotics. Clindamycin is added because it has been shown in mouse models of GABHS myositis to be more effective than penicillin in preventing death. However, it should not be used as monotherapy because of the potential for a small percentage of GABHS isolates to be resistant. For suspected type I NF, a combination of clindamycin with a third-generation cephalosporin, or ampicillin, gentamicin and metronidazole should be used. Antibiotics should be given for 10 full days. There is also evidence from case reports and one stratified case control study that intravenous immunoglobulin may be life-saving for patients meeting the case definition for STSS (27). A single dose of $2 \mathrm{~g} / \mathrm{kg} /$ day or doses of $400 \mathrm{mg} / \mathrm{kg}$ for up to five days have been used, but the most efficacious dosing and frequency of administration have not been determined.

\section{CHEMOPROPHYLAXIS OF CONTACTS OF PERSONS WITH GABHS-RELATED NF}

At a rate of $2.9 / 1000$ population, the risk of secondary related invasive GABHS disease (including NF) in household members of patients with invasive GABHS disease is almost 200 times that of the general population (4). Other authors have noted clusters of severe GABHS infection (28). This increased risk of disease among close contacts, and the high rates and severity of sequelae of NF have led most public health authorities in Canada to recommend that close household contacts (persons spending more than $4 \mathrm{~h} /$ day or $20 \mathrm{~h} /$ week together, sharing sleeping arrangements or having direct mucous membrane contact within seven days of illness of the index patient) of persons with severe group A streptococcal infections should receive chemoprophylaxis. Most authorities in Canada recommend prophylaxis with drugs such as penicillin, first-generation cephalosporins, clindamycin or erythromycin for 10 days. However, definitive studies of the benefit of chemoprophylaxis have not been conducted, and other jurisdictions suggest making decisions on a case by case basis (29). Rifampin, the usual chemotherapeutic agent for meningococcemia and Haemophilus influenzae disease, is poor at eradicating group A streptococcal carriage and is, thus, not recommended in the setting of GABHS-related NF disease (30).

\section{NONSTEROIDAL DRUGS AND TYPE II NF}

Some investigators have hypothesized that nonsteroidal anti-inflammatory drugs (NSAIDs) increase the risk of GABHS NF, particularly among children with varicella (14,31-33). This hypothesis has some biological plausibility because NSAIDs impair granulocyte function, including chemotaxis, phagocytosis and bactericidal activity (32). However, there have been no well controlled studies to deny or confirm such an association. One case control study (17) found that NSAID use was significantly more common among varicella and NF cases than among controls. However, in more than three- 
quarters of the cases, the NSAID use occurred following the onset of symptoms of secondary infection. This suggests an 'indication bias' and may be due to NSAIDS being given as a response to infection in persons with severe disease rather than a cause of the severity of the illness. The need to define clearly the temporal relationship between NSAID exposure and NF needs to be addressed in future studies evaluating a potential association. One study involving an NSAID and NF model in rabbits suggested that the apparently greater severity of NF in humans treated with an NSAID may be due to the therapeutic delay induced by the misleading clinical effects of the NSAID and not to inhibition of antibacterial defence (34).

\section{ADJUNCTIVE THERAPY}

$\mathrm{NF}$ and other severe GABHS infections may be associated with an absence of neutralizing antibody, and providing such antibody in normal immunoglobulin may be of value. There is level 2 and level 3 evidence from case reports and one stratified case control study that intravenous immunoglobulin may be life-saving in patients meeting the case definition for STSS $(27,35,36)$. Doses of up to $2 \mathrm{~g} / \mathrm{kg} / \mathrm{day}$ for one to five days have been used and have been shown to increase superantigen-neutralizing activity $(27,35)$. Hyperbaric oxygen (HBO) has been reported in case reports and case series $(25,37,38)$ to be useful as adjunctive therapy of Type $1 \mathrm{NF}$, but no controlled studies exist and its role in GABHS fasciitis is unknown. Two of 12 patients receiving as many as $12 \mathrm{HBO}$ treatments for GABHS NF (14) in one study developed complications, including an inadvertent extubation during transport from the chamber and an episode of severe bronchospasm. The use of HBO for the management of any type of NF should be considered to be experimental.

\section{CONCLUSION}

$\mathrm{NF}$ is a relatively rare but life- or organ-threatening condition that is a medical emergency. Type I NF is less common due to mixed bacteria and, often, is associated with intraabdominal infections or complications of surgery. Type II NF is due to GABHS. Both types require immediate surgical and medical intervention. The actual population-based rates of these diseases in Canada and their outcomes are areas in need of research.

\section{REFERENCES}

1. Canadian Paediatric Society. Invasive group A streptococcal infections. Paediatr Child Health 1999;4:73-6.

2. Kaul R, McGeer A, Low DE, Green K, Schwartz B. Population-based surveillance for group A streptococcal necrotizing fasciitis: Clinical features, prognostic indicators, and microbiologic analysis of seventy-seven cases. Ontario Group A Streptococcal Study. Am J Med 1997;103:18-24.

3. Giuliano A, Lewis F Jr, Hadley K, Blaisdell F. Bacteriology of necrotizing fasciitis. Am J Surg 1977;134:52-7.

4. Davies HD, McGeer A, Schwartz B, et al. Invasive group A streptococcal infections in Ontario, Canada. Ontario Group A Streptococcal Study Group. N Engl J Med 1996;335:547-54.

5. Defining the group A streptococcal toxic shock syndrome. Rationale and consensus definition. The Working Group on Severe Streptococcal Infections. JAMA 1993;269:390-1.

6. Health Canada. Necrotizing Fasciitis/Myositis ("flesh-eating disease") <http://www.hc-sc.gc.ca/hpb/lcdc/bid/ respdis/necro_e.html> (version current at January 2001)

7. Laupland KB, Davies HD, Low DE, Schwartz B, Green K, McGeer A. Invasive group A streptococcal disease in children and association with varicella-zoster virus infection. Ontario Group A Streptococcal Study Group. Pediatrics 2000;105:E60.

8. Lally KP, Atkinson JB, Woolley MM, Mahour GH. Necrotizing fasciitis. A serious sequela of omphalitis in the newborn. Ann Surg 1984;199:101-3.

9. Casali RE, Tucker WE, Petrino RA, Westbrook KC, Read RC. Postoperative necrotizing fasciitis of the abdominal wall. Am J Surg 1980;140:787-90.

10. Brook I. Microbiology of necrotizing fasciitis associated with omphalitis in the newborn infant. J Perinatol 1998;18:28-30.

11. Davies HD, Schwartz B. Invasive group A streptococcal infections in children. Adv Pediatr Infect Dis 1999;14:129-45.

12. Hsieh T, Samson LM, Jabbour M, Osmond MH. Necrotizing fasciitis in children in eastern Ontario: A case-control study. CMAJ 2000;163:393-6.

13. Davies H, Laupland K. Invasive streptococcal infection following varicella infection. Vaccines 2000;3:13-4.

14. Brogan TV, Nizet V, Waldhausen JH, Rubens CE, Clarke WR. Group A streptococcal necrotizing fasciitis complicating primary varicella: A series of fourteen patients. Pediatr Infect Dis J 1995;14:588-94.

15. Givner LB. Invasive disease due to group A beta-hemolytic streptococci: Continued occurrence in children in North Carolina. South Med J 1998;91:333-7.

16. Zurawski CA, Bardsley M, Beall B, et al. Invasive group A streptococcal disease in metropolitan Atlanta: A population-based assessment. Clin Infect Dis 1998;27:150-7.

17. Zerr DM, Alexander ER, Duchin JS, Koutsky LA, Rubens CE. A case-control study of necrotizing fasciitis during primary varicella. Pediatrics 1999;103:783-90.

18. Wheeler MC, Roe MH, Kaplan EL, Schlievert PM, Todd JK. Outbreak of group A streptococcus septicemia in children. Clinical, epidemiologic, and microbiological correlates. JAMA 1991;266:533-7.

19. Davies HD, Matlow A, Scriver SR, et al. Apparent lower rates of streptococcal toxic shock syndrome and lower mortality in children with invasive group A streptococcal infections compared with adults. Pediatr Infect Dis J 1994;13:49-56.

20. Kuhn S, Davies H, Jadavji T. Varicella zoster virus infections in Canadian children in the pre-vaccine era: A hospital based study. Can J Infect Dis 1997;8:323-8.

21. Walsh M, Chodock R, Quinn C, Peglow S. Group A beta-hemolytic streptococcal meningitis associated with uncomplicated varicella. Am J Emerg Med 1994;12:602-3.

22. Vugia DJ, Peterson CL, Meyers HB, et al. Invasive group A streptococcal infections in children with varicella in southern California. Pediatr Infect Dis J 1996;15:146-50.

23. Peterson CL, Vugia DJ, Meyers HB, et al. Risk factors for invasive group A streptococcal infections in children with varicella: A case-control study. Pediatr Infect Dis J 1996;15:151-6.

24. Stamenkovic I, Lew PD. Early recognition of potentially fatal necrotizing fasciitis. The use of frozen-section biopsy. N Engl J Med 1984;310:1689-93.

25. Sawin RS, Schaller RT, Tapper D, Morgan A, Cahill J. Early recognition of neonatal abdominal wall necrotizing fasciitis. Am J Surg 1994;167:481-4.

26. Arslan A, Pierre-Jerome C, Borthne A. Necrotizing fasciitis: Unreliable MRI findings in the preoperative diagnosis. Eur J Radiol 2000;36:139-43.

27. Kaul R, McGeer A, Norrby-Teglund A, et al. Intravenous immunoglobulin therapy for streptococcal toxic shock syndrome - a comparative observational study. The Canadian Streptococcal Study Group. Clin Infect Dis 1999;28:800-7.

28. Gamba MA, Martinelli M, Schaad HJ, et al. Familial transmission of a serious disease-producing group A streptococcus clone: Case reports and review. Clin Infect Dis 1997;24:1118-21.

29. American Academy of Pediatrics. Group A streptococcal infections. In: Pickering L, ed. 2000 Red Book: Report of the Committee on Infectious Diseases, 25 th edn. Elk Grove Village: American Academy of Pediatrics, 2000:535. 
30. Davies HD, Low DE, Schwartz B, et al. Evaluation of shortcourse therapy with cefixime or rifampin for eradication of pharyngeally carried group A streptococci. Ontario GAS Study Group. Clin Infect Dis 1995;21:1294-9.

31. Krige JE, Spence RA, Potter PC, Terblanche J. Necrotising fasciitis after diflunisal for minor injury. Lancet 1985;ii:1432-3.

32. Brun-Buisson CJ, Saada M, Trunet P, Rapin M, Roujeau JC, Revuz J. Haemolytic streptococcal gangrene and non-steroidal anti-inflammatory drugs. Br Med J (Clin Res Ed) 1985;290:1786.

33. Stevens DL. Could nonsteroidal antiinflammatory drugs (NSAIDs) enhance the progression of bacterial infections to toxic shock syndrome? Clin Infect Dis 1995;21:977-80.

34. Guibal F, Muffat-Joly M, Terris B, Garry L, Morel P, Carbon C. Effects of diclofenac on experimental streptococcal necrotizing fasciitis (NF) in rabbit. Arch Dermatol Res 1998;290:628-33.

35. Barry W, Hudgins L, Donta ST, Pesanti EL. Intravenous immunoglobulin therapy for toxic shock syndrome. JAMA 1992;267:3315-6.

36. Norrby-Teglund A, Kaul R, Low DE, et al. Plasma from patients with severe invasive group A streptococcal infections treated with normal polyspecific IgG inhibits streptococcal superantigeninduced $\mathrm{T}$ cell proliferation and cytokine production. J Immunol 1996;156:3057-64.

37. Gozal D, Ziser A, Shupak A, Ariel A, Melamed Y. Necrotizing fasciitis. Arch Surg 1986;121:233-5.

38. Hirn M. Hyperbaric oxygen in the treatment of gas gangrene and perineal necrotizing fasciitis. A clinical and experimental study. Eur J Surg Suppl 1993;13:1-36.

\section{INFECTIOUS DISEASES AND IMMUNIZATION COMMITTEE}

Members: Drs Upton Allen, The Hospital for Sick Children, Toronto, Ontario; H Dele Davies, Division of Infectious Diseases, Alberta Children's Hospital, Calgary, Alberta; Gilles Delage, Epidemiology and Microbiology, Hema-Quebec, Saint-Laurent, Quebec (chair, 1996-2000); Joanne Embree, The University of Manitoba, Winnipeg, Manitoba (chair); Mireille Lemay, Department of Infectious Diseases, Sainte-Justine Hospital, Montreal, Quebec; Charles Morin, Complexe hospitalier Sagamie, Chicoutimi, Quebec (director responsible, 1997-2000); Gary Pekeles, The Montreal Children's Hospital, Montreal, Quebec (director responsible); Ben Tan, Division of Infectious Diseases, Royal University Hospital, University of Saskatchewan, Saskatoon, Saskatchewan (1994-2000)

Consultants: Drs Noni MacDonald, Faculty of Medicine, Dalhousie University, Halifax, Nova Scotia; Victor Marchessault, Cumberland, Ontario Liaisons: Drs Scott Halperin, Department of Pediatrics, IWK-Grace Health Centre, Halifax, Nova Scotia (IMPACT); Susan King, Division of Infectious Diseases, The Hospital for Sick Children, Toronto, Ontario (Canadian Paediatric AIDS Research Group); Monique Landry, Direction de la santé publique de Laval, Laval, Quebec (Public Health); Larry Pickering, Centre for Pediatric Research, Norfolk, Virginia (American Academy of Pediatrics); John Waters, Alberta Health, Edmonton, Alberta (Epidemiology) Principal author: Dr H Dele Davies, Division of Infectious Diseases, Alberta Children's Hospital, Calgary, Alberta

The recommendations in this statement do not indicate an exclusive course of treatment or procedure to be followed. Variations, taking into account individual circumstances, may be appropriate.

Internet addresses are current at the time of publication.

This article also appears in Paediatr Child Health 2001;6(5):243-247. 


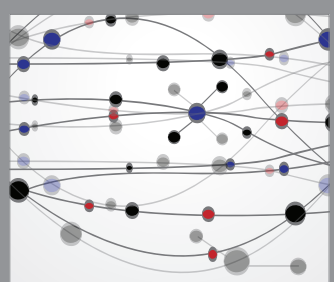

The Scientific World Journal
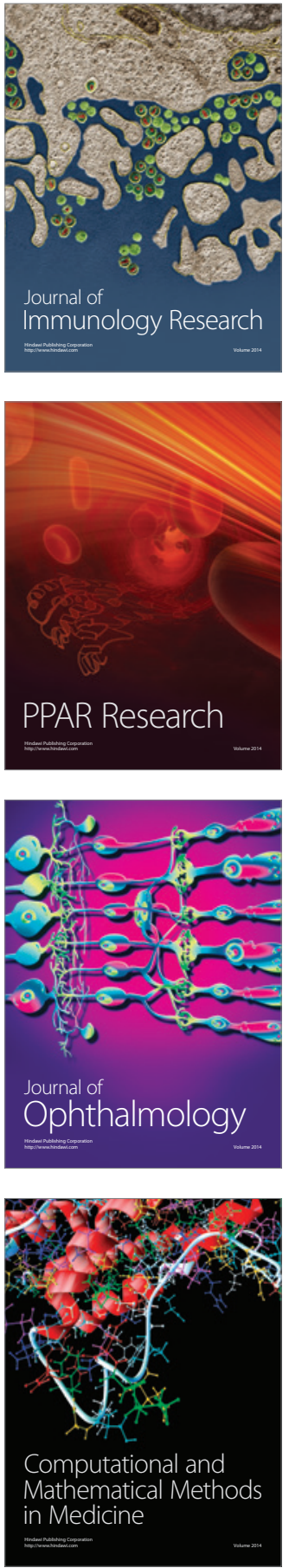

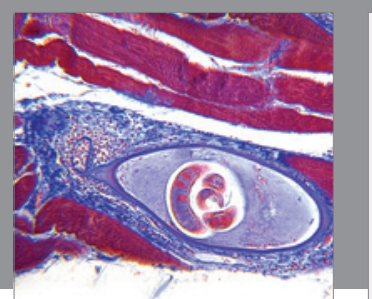

Gastroenterology Research and Practice

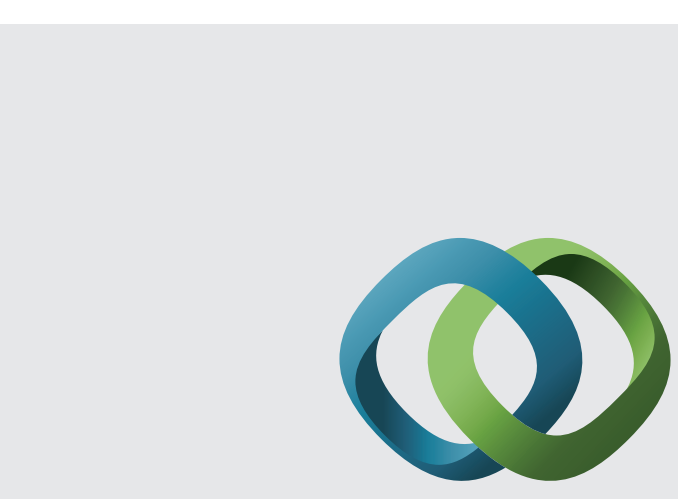

\section{Hindawi}

Submit your manuscripts at

http://www.hindawi.com
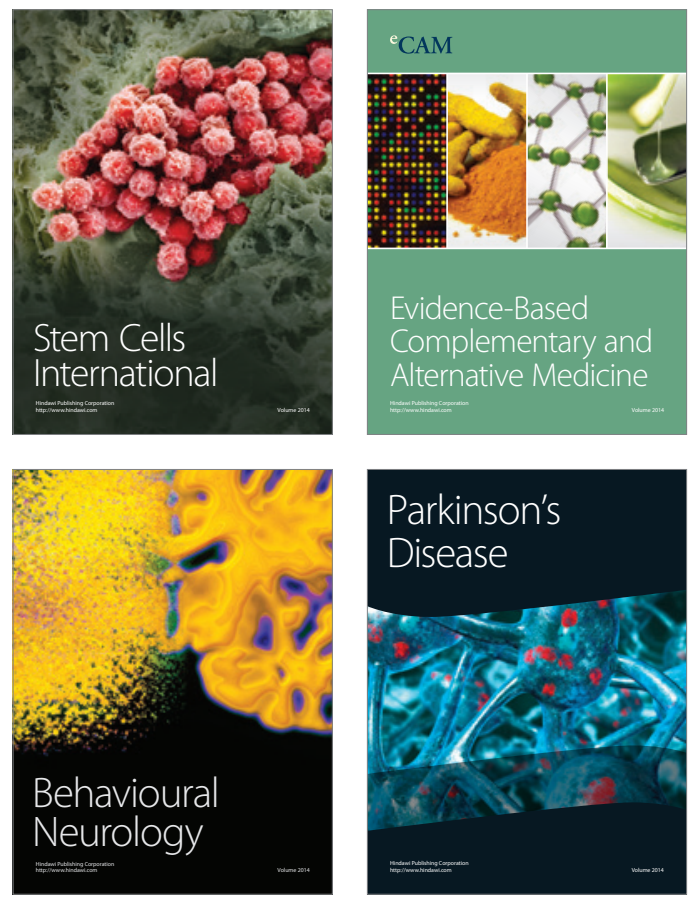
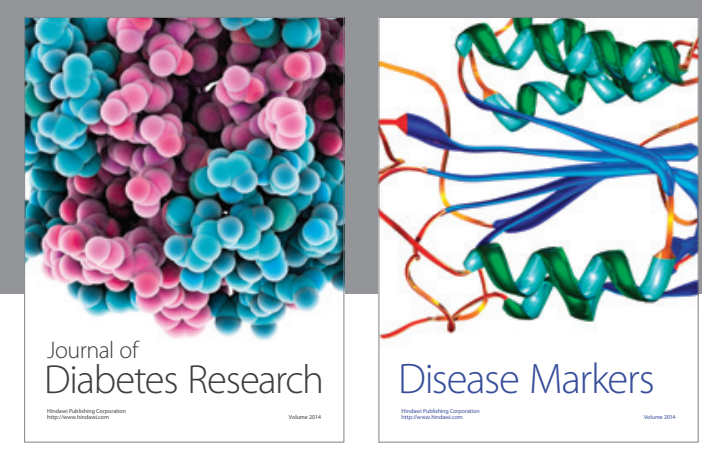

Disease Markers
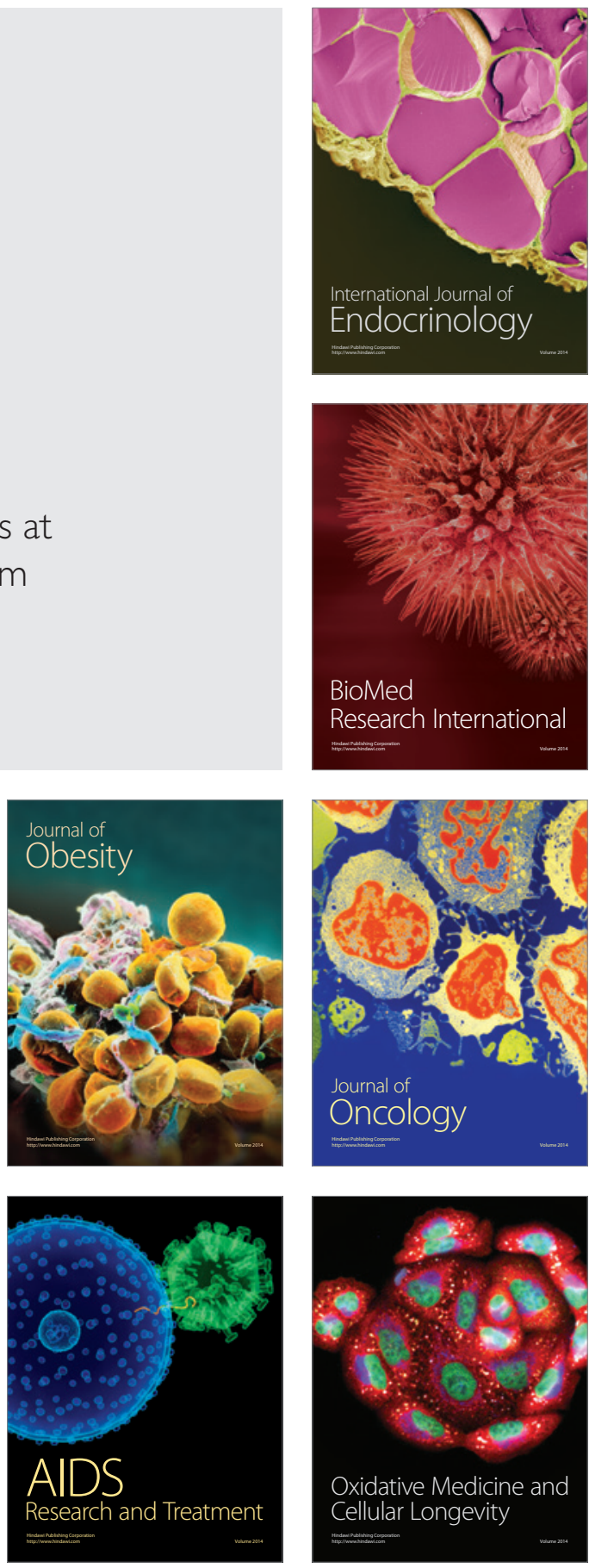